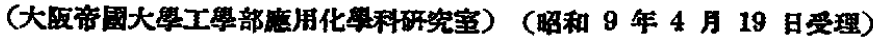

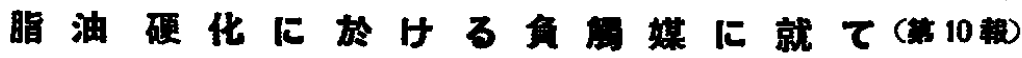

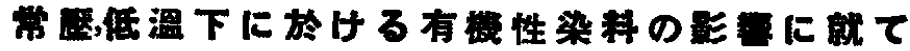

上 野 誠 -

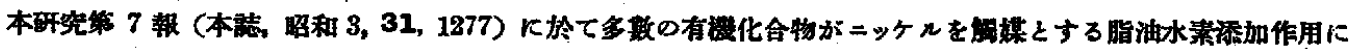

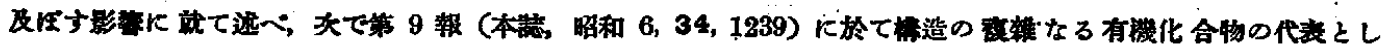

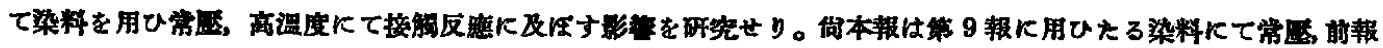

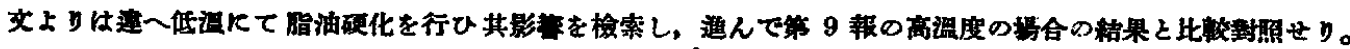

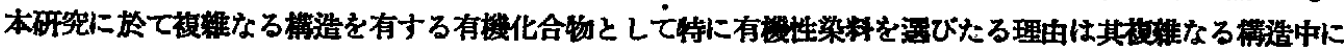

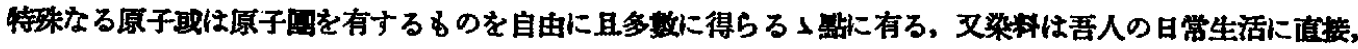

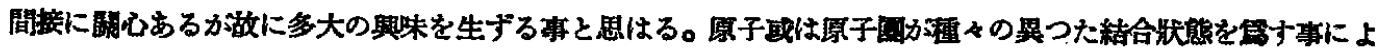

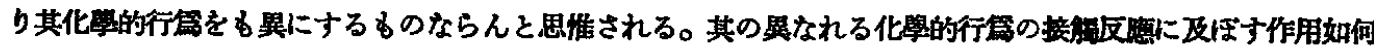

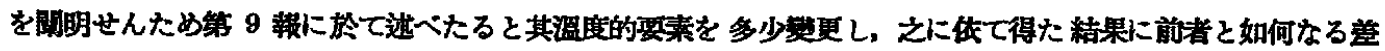

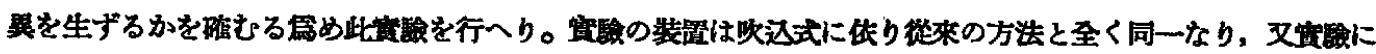

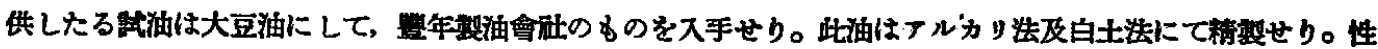
狀等大の如し。

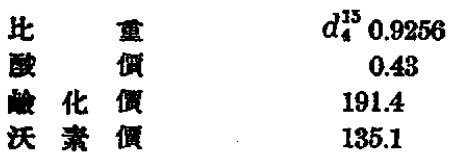

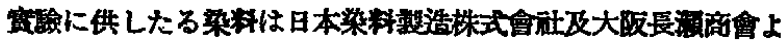

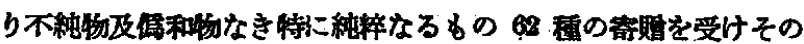

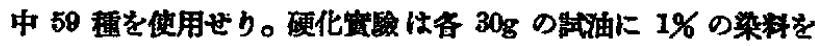

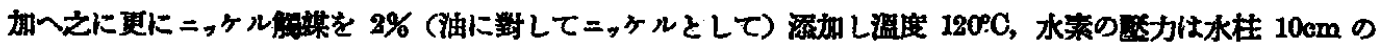

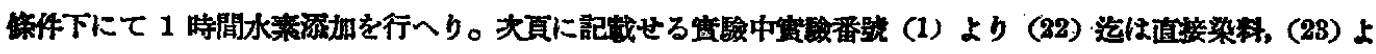

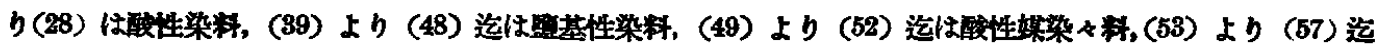

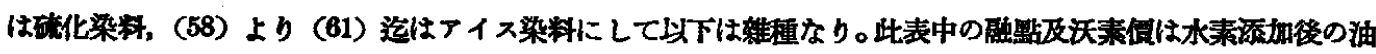

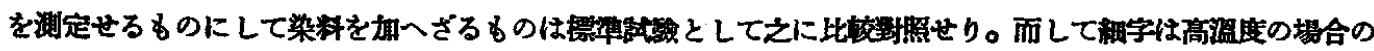

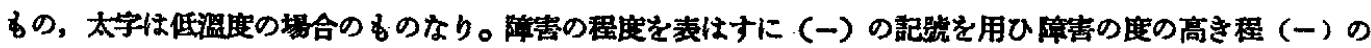

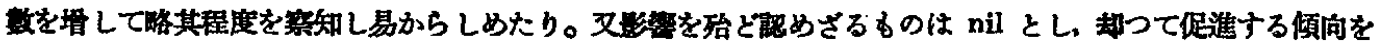

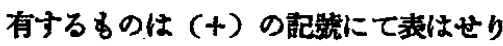

結 論

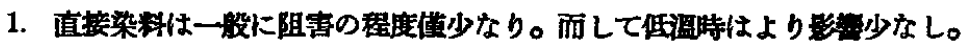

2. 酸性染粦は 2～3 の例外を除き低温の場合に障害少なし。

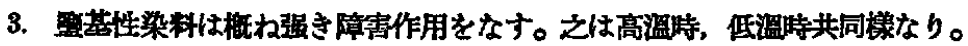

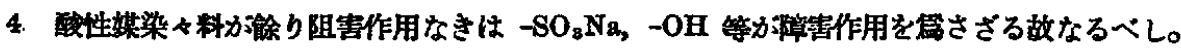

5. 硫化染料は其中に存する $\mathrm{S}$ カ抗措作用を管むるのと考へらる。

6. フイス染料中 $-\mathrm{NO}_{2}$ の存するすのは强き障害作用を星す。 


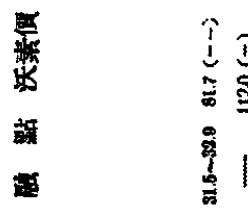

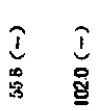

施

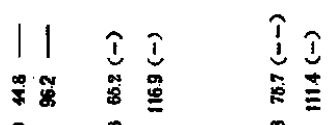

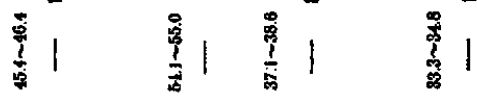

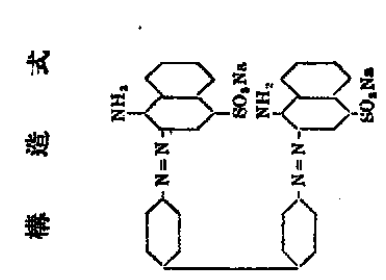

$=$

衰

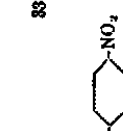

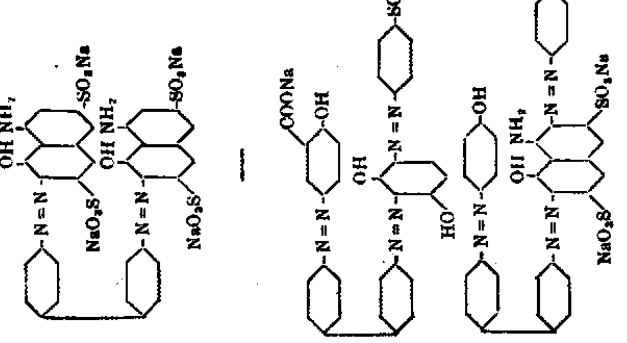

敖

籍

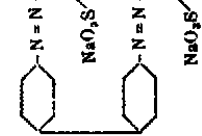

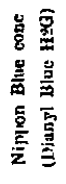

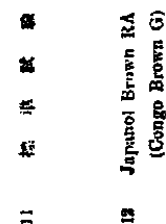

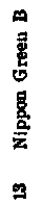

造

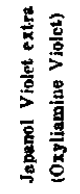

so

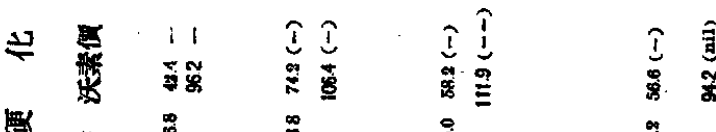

产兽

$\stackrel{\hat{1}}{\hat{\imath}}$

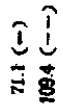

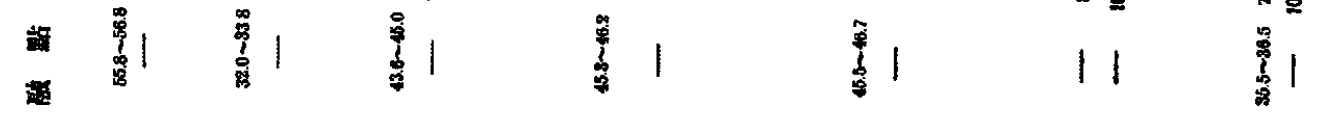

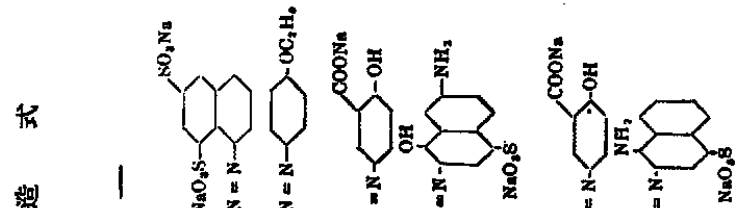
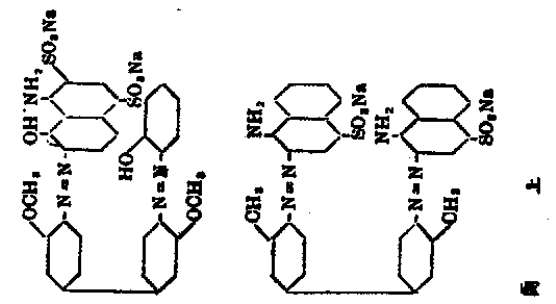

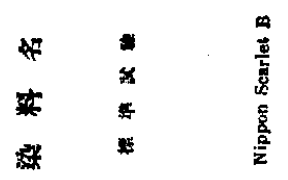

产

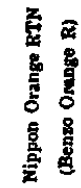

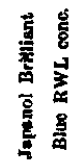

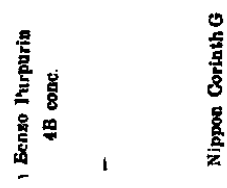

琵 


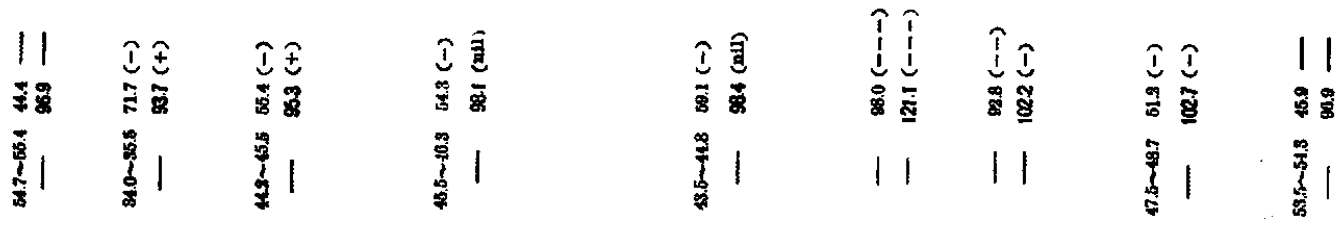

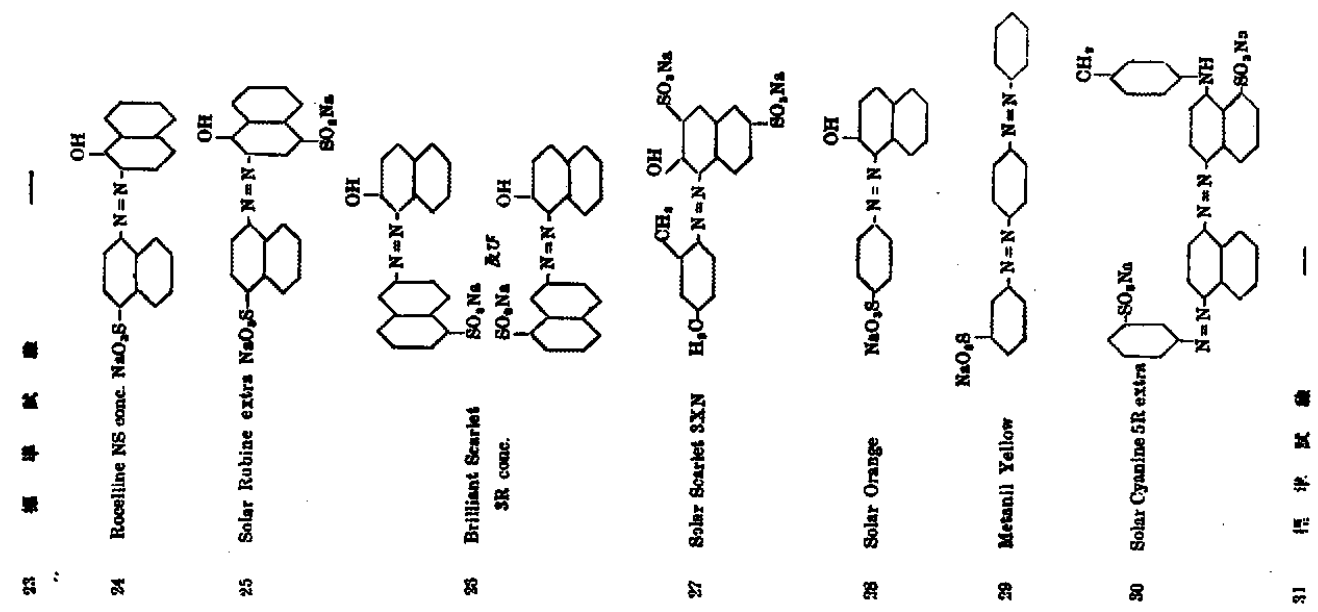

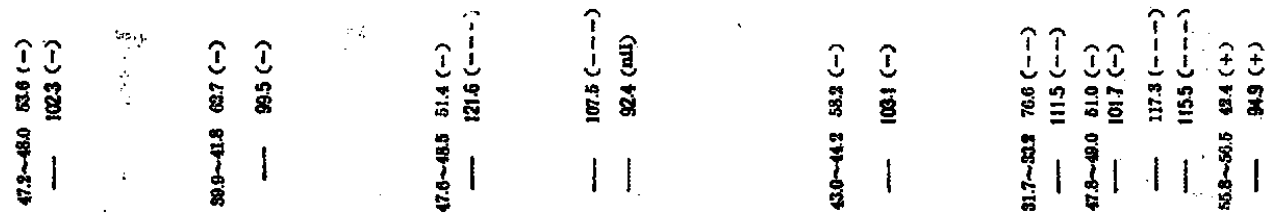

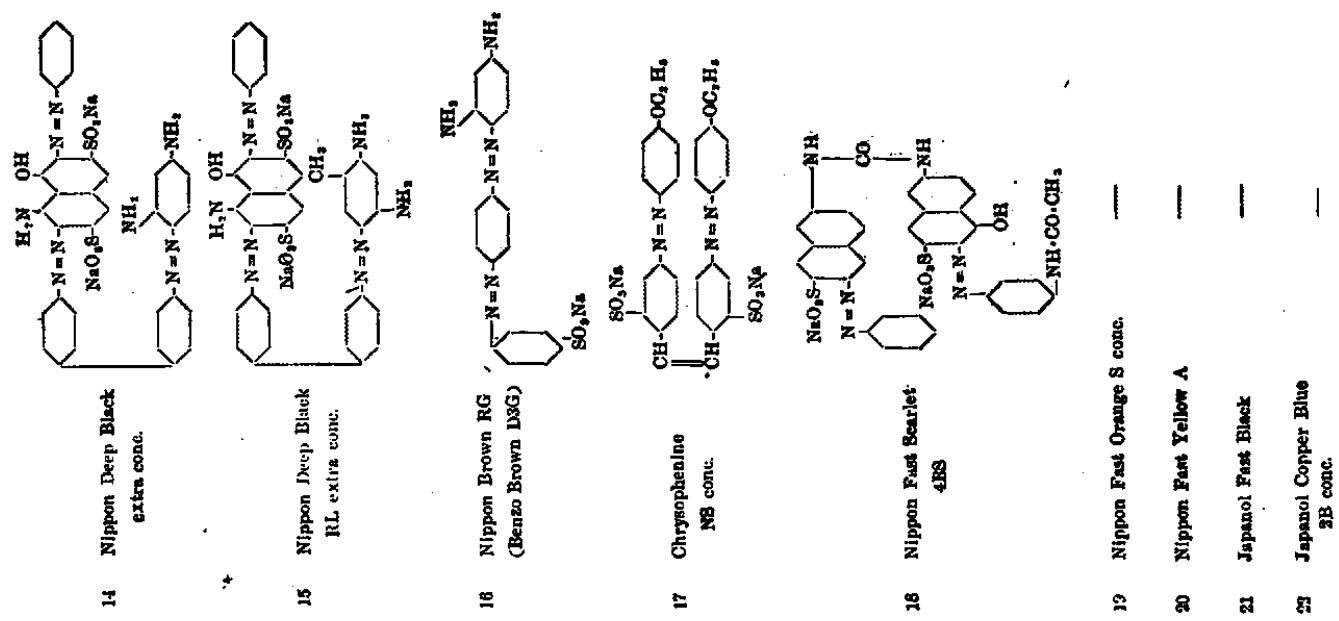




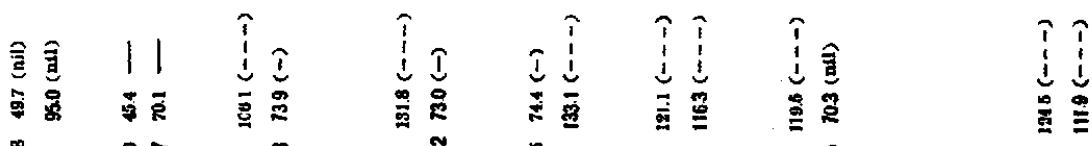

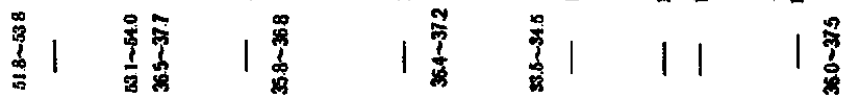

11

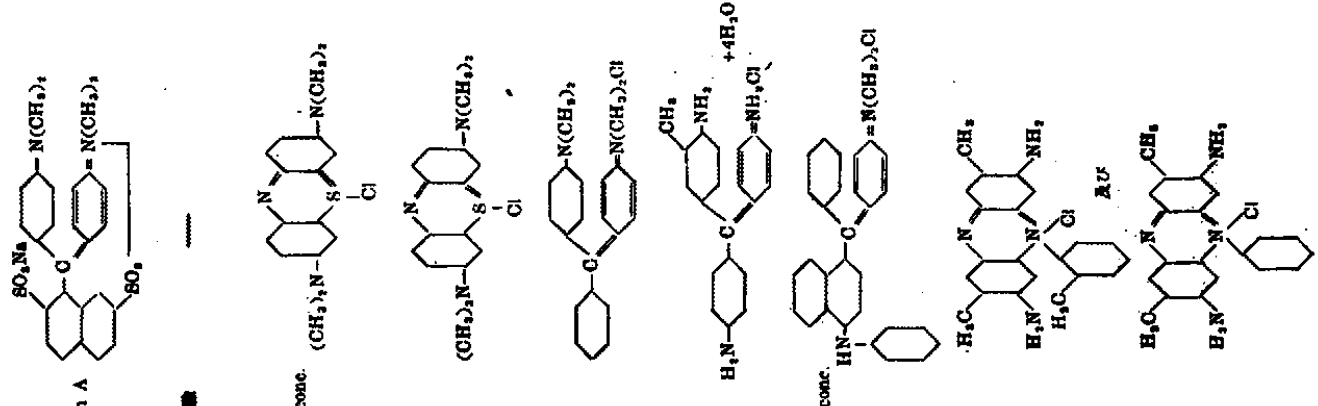

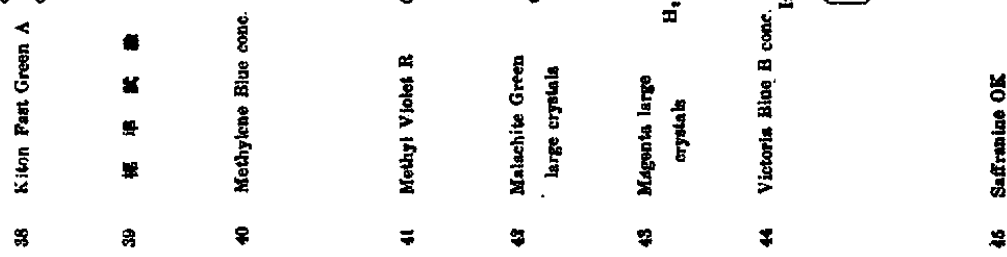

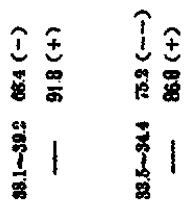

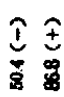

1

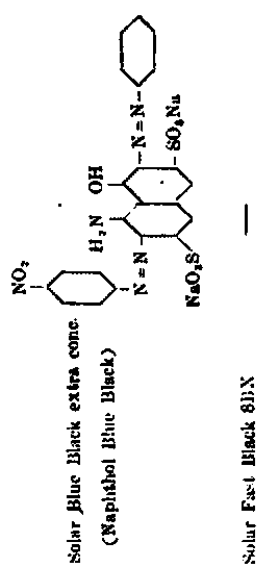

a
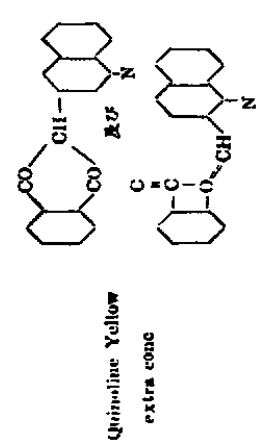

F
ไิ่

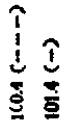

11
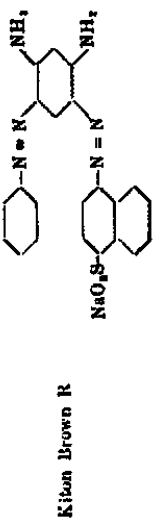

$\infty$

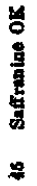

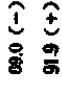

管

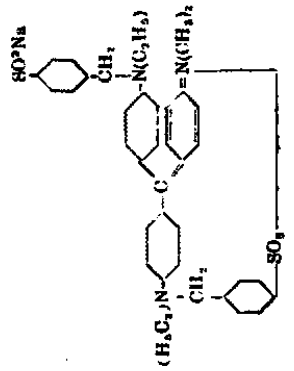

בְ.

5 


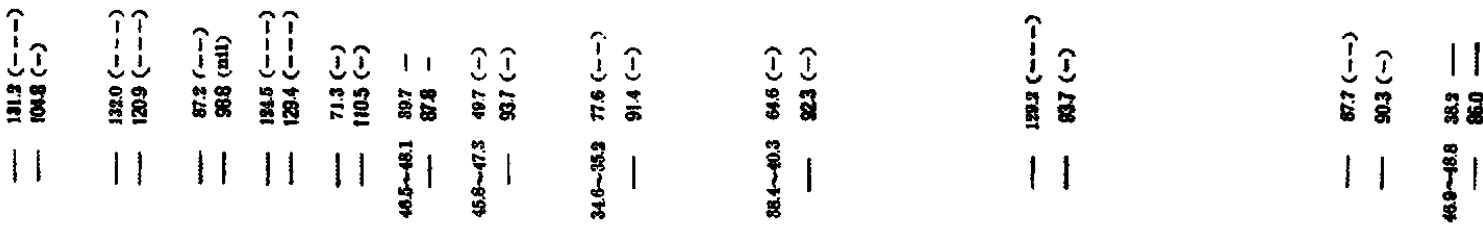

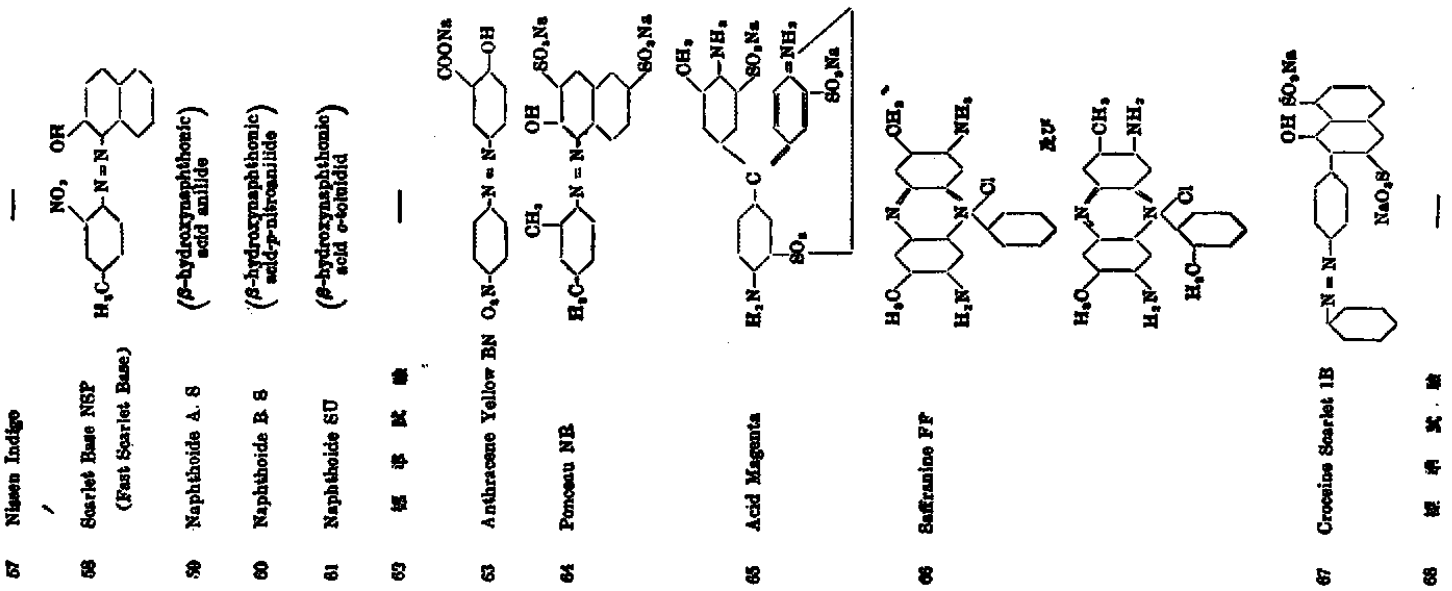

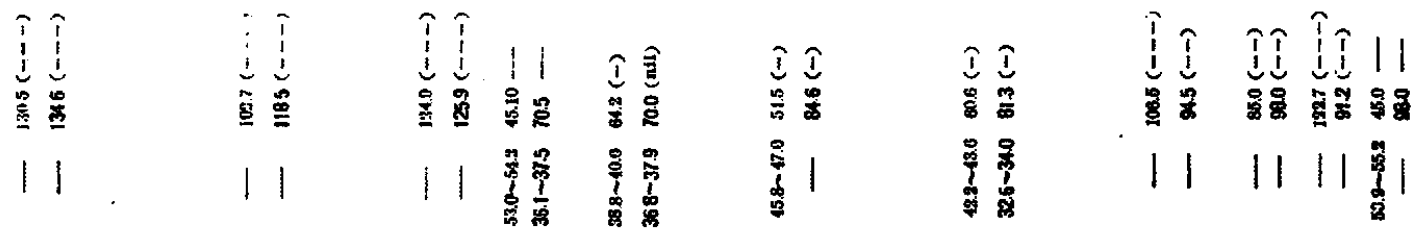

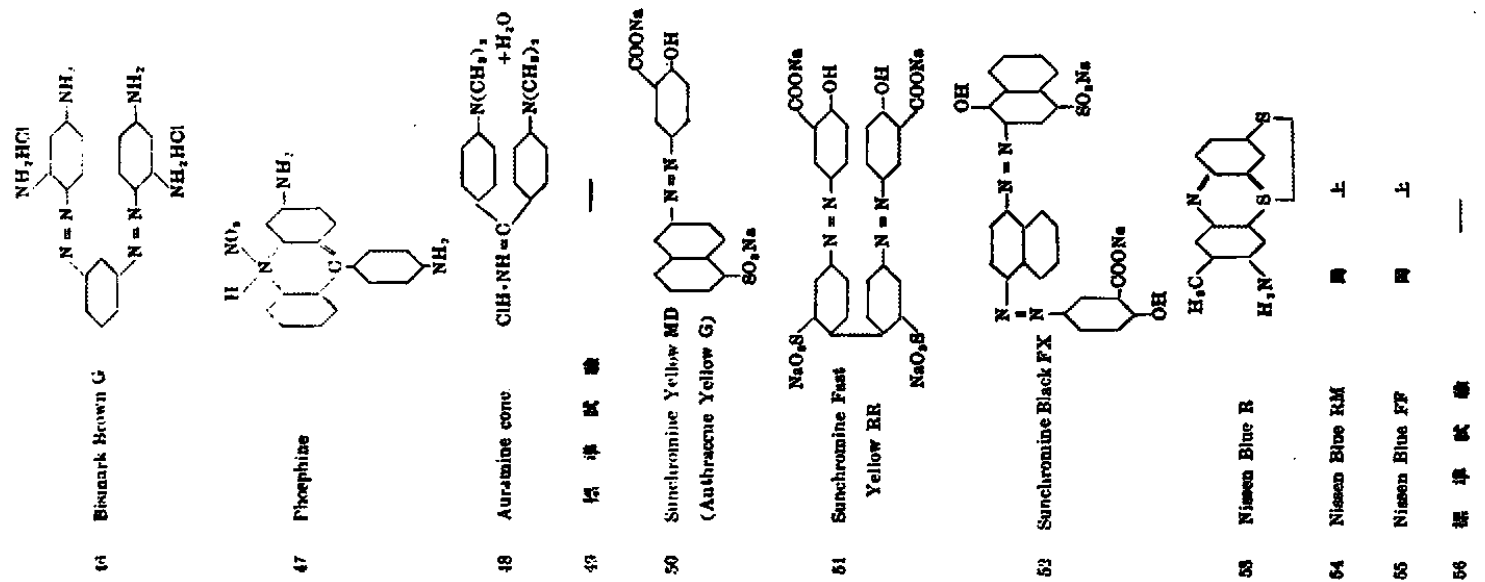


7.一般に $-\mathrm{OH},-\mathrm{SO}_{2} \mathrm{Na},-\mathrm{COONa}$ 等が存するときは影祭少なく, 又 $\mathrm{NH}_{2},-\mathrm{NO}_{2}$ 等力洊すれはば激しき負 触桇の性翼を示ち。

8. 然し $-\mathrm{NH}_{2}$ と $-\mathrm{OH}$ 或は $-\mathrm{NO}_{2}$ と $-\mathrm{NH}_{2}$ 等共存子る場合には却つて阻害を济少する㑯向を有す。

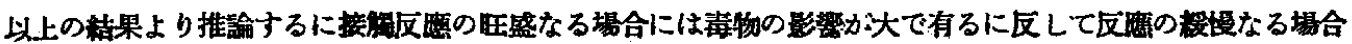

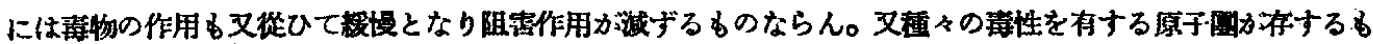

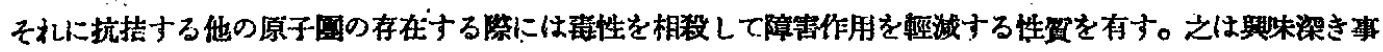
察と考へらる。

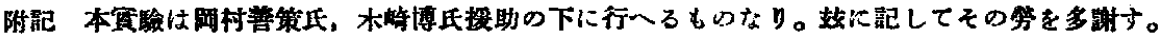

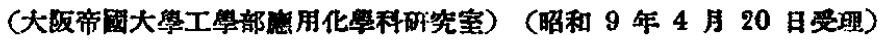

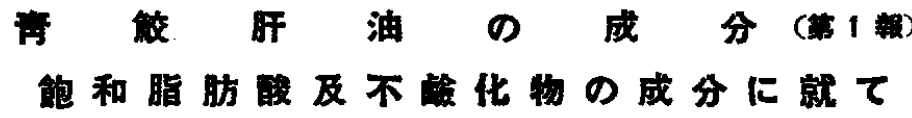

上野 誠一・生田 治一”。

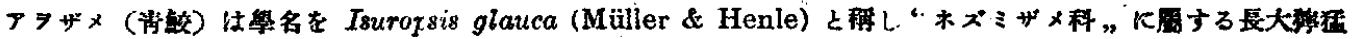

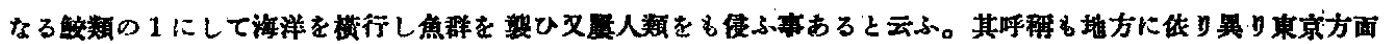

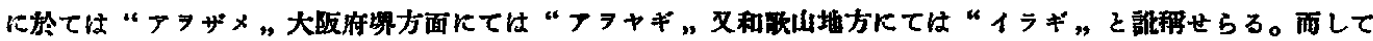

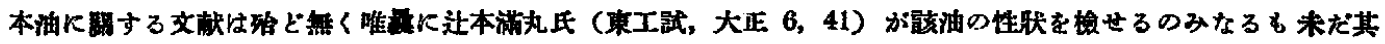

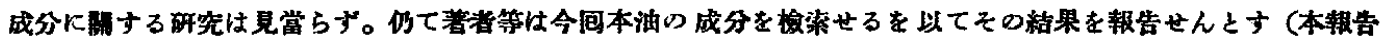

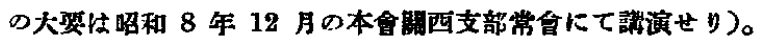

\section{葢 驗之部}

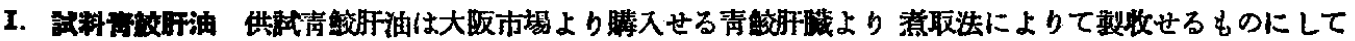
淡黄色の液县なれどる常温又は冬季に於ては多量の固形物を析出せり。一般性狀は下距の如くにして辻本氏の

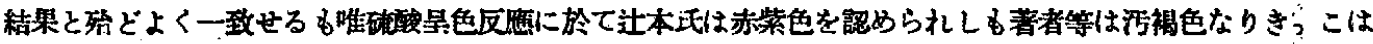

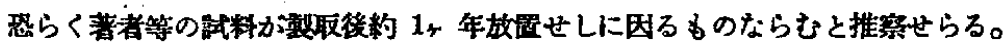

\begin{tabular}{|c|c|c|c|c|c|}
\hline & 著者等 & 沚本氏 & & 著者等 & 式本氒 \\
\hline 此 西 $\left(d_{4}^{15}\right)$ & 0.9176 & 0.9178 & 沃素價(ウィイス氏法) & 113.9 & 109.3 \\
\hline 屈折犁 $n_{\text {. }}^{20}$ & 1.4736 & 1.4741 & 不觡化物(\%) & 1.6 & 1.7 \\
\hline 酸作 & 9.8 & 0.5 & 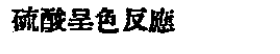 & 污蝎色 & 赤柴色 \\
\hline
\end{tabular}

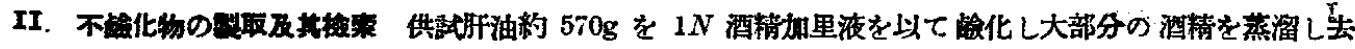

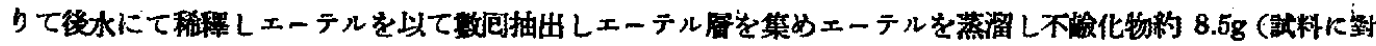

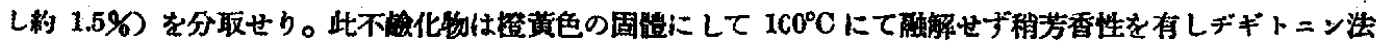

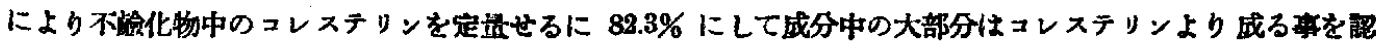

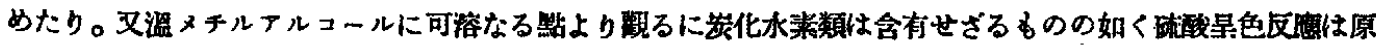

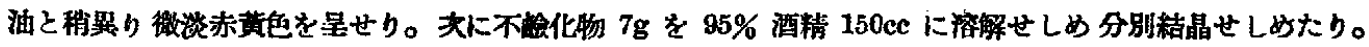

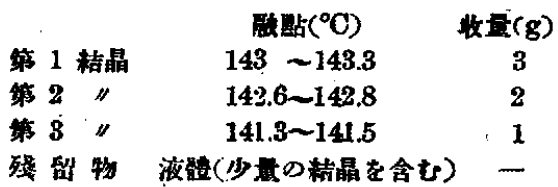

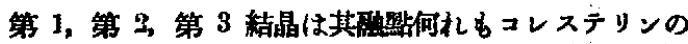
臂紫 $\left(148^{\circ} \mathrm{C}\right)$ より可成り氐し，仍て更に上記 3 結晶を

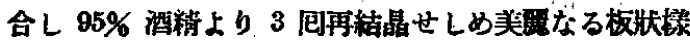

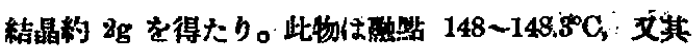

